\title{
La información medioambiental en los periódicos nacionales de Colombia y España: un estudio comparativo
}

\section{The environmental information in the national newspapers from Colombia and Spain: a comparative analysis}

\section{A informação ambiental nos jornais nacionais da Colômbia e Espanha: um estudo comparativo}

\author{
Antonia Moreno-Cano ${ }^{1}$, Lizandro Angulo-Rincón ${ }^{2}$
}

Forma de citar: A. Moreno-Cano, L. Angulo-Rincón, "La información medioambiental en los periódicos nacionales de Colombia y España: un estudio comparativo”, Respuestas, vol. 20, no. 2, pp. 34-53, 2015.

Recibido:

Diciembre 10 de 2014

Aceptado:

Mayo 22 de 2015

\section{Resumen}

Antecedentes: La comunicación ambiental ha sido objeto de estudio de la academia y del periodismo desde la década del 70, tanto en Colombia como en España, pues coincide con la difusión del informe Límites al Crecimiento del Club de Roma y la Cumbre de la Tierra en Estocolmo en el mismo año. A partir de allí, este tipo de periodismo ha tratado de transitar hacia la calidad informativa, gracias a los estudios académicos de universidades y centros de investigación. Objetivo: este trabajo pretende establecer equivalencias comparativas entre El Espectador de Colombia y El País de España, los elegidos para la muestra, con el fin de conocer las debilidades y fortalezas que poseen los contenidos ambientales en ambos diarios. Método: se utiliza el método del análisis de contenido, con enfoque cuantitativo, de manera que permita identificar la importancia, calidad, frecuencia y forma de exposición que se concede a la información y opinión relacionada con el medio ambiente. Aquí se emplea una muestra aleatoria sistemática de semanas compuestas del 2009 y 2010, con el fin de que haya una amplia representatividad de estos contenidos ambientales publicados en cada uno de los meses de esos dos años. Resultados: se muestran similitudes y diferencias notables en los dos medios de comunicación. Las similitudes se refieren al uso de las noticias como principal género periodístico, la no presencia de sensacionalismo en las piezas informativas, la escasa identificación de responsables por la falta de conciencia ambiental y la dependencia hacia las fuentes gubernamentales. Conclusión: en los dos casos, es necesario que sus directivos y periodistas asuman una posición más crítica y comprometida para que los lectores cuenten con información de calidad que los motive a adoptar estilos de vida ambientalmente sostenibles.

Palabras clave: Análisis de Contenido, Divulgación Científica, Medio Ambiente, Periódicos, Periodismo Especializado.

\begin{abstract}
Background: Environmental communication has been studied in academia and journalism since the 70s, both in Colombia and in Spain, as it coincides with the divulgation of
\end{abstract}


the report 'Limits to the Growth of Rome's Club and the Earth Summit in Stockholm in the same year. Since then, this type of journalism has attempted to move towards the quality of information, thanks to academic studies at universities and research centers. Objective: This paper aims to establish comparative equivalences between El Espectador of Colombia and El Pais in Spain, the newspapers chosen for the sample, in order to know the weaknesses and strengths on the environmental content in both newspapers. Method: Content analysis method was used, with a quantitative approach, such that allows to identify the importance, quality, frequency and way of exposure given to the information and opinion related to environment. A weekly basis composed systematic random sample from 2009 and 2010 was utilized, in order to have a broad representation of these environmental contents published on each of the months of those two years. Results: Similarities and important differences in the two media are shown. The similarities relate to the use of news as the main journalistic genre, the non-presence of sensationalism in the pieces of news, poor identification of those responsible for the lack of environmental consciousness and dependence on government sources. Conclusion: In both cases, it is necessary that directors and journalists adopt a more critical and committed role for the readers to have quality information that motivates them to adopt environmentally sustainable life styles.

Keywords: Content Analysis, Newspapers, Environmental, Specialized Journalism, Scientific Communication.

\section{Resumo}

Antecedentes: A comunicação ambiental tem sido objeto de estudo das universidades e do jornalismo tanto na Colômbia quanto na Espanha, desde a década de 70, pois tem coincidido com a difusão do relatório "Limites ao Crescimento do Club de Roma" e a "Conferencia da Terra" em Estocolmo no mesmo ano. A partir de aí, este tipo de jornalismo tem tratado de transitar na busca da qualidade informativa, graças aos estudos académicos de universidades e centros de pesquisa. Objetivo: este trabalho pretendeu estabelecer equivalências comparativas entre os jornais "El Espectador" da Colômbia e "El País" da Espanha, os elegidos para a amostra, com o fim de conhecer as debilidades e fortalezas que possuem os conteúdos ambientais nestes jornais. Método: utilizou-se o método da análise de conteúdo, com enfoque quantitativo, de maneira que permitisse identificar a importância, qualidade, frequência e forma de exposição que se concede à informação e opinião relacionada com o ambiente. Utilizou-se uma amostra aleatória sistemática de semanas composta dos anos 2009 e 2010, com o propósito de que tiver uma ampla representatividade destes conteúdos ambientais publicados em cada um dos meses desses dois anos. Resultados: apreciaram-se similitudes e diferenças notáveis nos dois jornais. As similitudes se referem ao uso das notícias como principal género jornalístico, a não presença de sensacionalismo nas peças informativas, a escassa identificação de responsáveis pela falta de consciência ambiental e a dependência das fontes governamentais. Conclusão: em ambos os casos, é necessário que seus diretivos e jornalistas assumam uma posição mais crítica e comprometida para que os leitores contem com informação de qualidade que os motive a adoptar estilos de vida ambientalmente sustentáveis.

Palavras-chave: Análise de Conteúdo, Ambiente, Divulgação Científica, Jornais, Jornalismo Especializado.
ISSN 0122-820X

E-ISSN 2422-5053

PP: $34-53$ 
No. 2

Julio - Diciembre 2015 ISSN 0122-820X E-ISSN 2422-5053 PP: 34-53

\section{Introducción}

Este estudio diagnostica el periodismo ambiental que se ejerce en los periódicos nacionales generalistas El Espectador de Colombia y El País de España, con el fin de determinar si sus contenidos transitan hacia la calidad. Cabe recordar que la información medioambiental toma más relevancia a medida que pasa el tiempo y en especial por el cambio climático, la minería irresponsable y la sobreexplotación de los recursos naturales, cuyas manifestaciones alrededor del planeta están alterando los ecosistemas y, por ende, la vida del ser humano.

La investigación se ciñe al método científico avalado por la comunidad académica y se lleva a cabo en varios apartados. El primero de ellos, se refiere al estado del arte en el que se desarrollan conceptos clave como el periodismo ambiental, el cambio climático y el desarrollo sostenible.

El segundo apartado tiene que ver que las preguntas de investigación. Aquí se busca un análisis del conjunto de las piezas, específicamente en lo referido a temas, subtemas, tipos de titular, los autores de los textos, y si son divulgativos o no, entre otras variables.

El tercer apartado nos remite al diseño metodológico, en el que se especifica el tipo de muestra de medios y contenidos utilizada -aleatoria sistemática de semanas compuestas-, y la muestra temporal -2 años: 2009 y 2010, para los dos periódicos estudiados. En este punto hay que recordar que la técnica de extracción de datos es el análisis de contenido cuantitativo, complementado con la aplicación de la escala de Budd, actualizada, con la que se mide la importancia que los periódicos le dan a la información medioambiental.

\section{Corpus Teórico}

\subsection{Periodismo Ambiental}

El Periodismo Ambiental es un crisol de información en el que entran innumerables asuntos con enorme trascendencia sobre el futuro del planeta y que suele tener repercusiones en otros ámbitos informativos como el político, el económico, el local, el nacional o el internacional entre otros [1].

La designación de Periodismo Ambiental [2] aparece en España a finales de 1994, coincidiendo con la creación de la Asociación de Periodistas de Información Ambiental, y se ha consensuado a lo largo de los años entre los profesionales de la información, frente a otras alternativas que se presentaron, como la de periodismo ecológico, medioambiental o verde.

Aunque ha habido cierta controversia para definir el término, Periodismo Ambiental, nos parece importante destacar su importancia con las palabras que se recogen [3] acerca del mismo: "se trata de una especialización periodística que se ocupa de la información de actualidad generada por la interacción del ser humano con los seres vivos y con su entorno, tanto el natural como el creado por el propio hombre".

Se entiende como Periodismo Ambiental [4] aquél que se ocupa de la información de actualidad que contextualice, analice los procesos y enumere los efectos de aquellas intervenciones relacionadas con "la naturaleza y el medio ambiente y en especial de aquellos aspectos que tienen que ver con su degradación".

El Periodismo Ambiental [5] ha adquirido ya suficiente madurez para considerarse periodismo especializado. Cuenta con requisitos precisos: experiencia en la aplicación de una metodología periodística de investigación, asociaciones de profesionales, 
una función social importante y una demanda específica de la sociedad.

En cuanto a las temáticas que aborda el Periodismo Ambiental [6], se elaboró un glosario de contenidos que van desde: "residuos, agua, bosques, conservacionismo, mares, costas, suelo, energía, transporte, atmósfera, problemas urbanos, agricultura, nuevas tecnologías, la complejidad de la Administración ambiental, organizaciones ecologistas, desarrollo sostenible, turismo y su impacto, seguimiento de los estudios de impacto y problemas de población”.

En el ejercicio del periodismo científico [7], que vamos a hacer extensible también al ambiental, los científicos se sienten representados de manera injusta y descontextualizada por los medios de comunicación, mientras que los periodistas, en líneas generales, sentimos que los científicos no saben comunicar. En realidad hay muchas similitudes entre ambos colectivos, pero tal vez, lo que más nos diferencia es la mirada que hacemos al mundo que nos rodea. La especialización del comunicador se está ofreciendo gradualmente en las universidades sólo en los últimos años, mientras que para los científicos la formación académica es un requisito fundamental. Además sus ritmos de trabajo son diferentes en cuanto a los tiempos que manejan. Ambos deben llegar a un consenso para que la información que se publica, en este caso sobre medio ambiente, sea la más certera y llegue de forma más clara a las diferentes audiencias.

Uno de los papeles del Periodismo Ambiental, largamente considerado, es el de perro guardián (watchdog), que salvaguarda los intereses públicos frente a amenazas, $\mathrm{y}$ que posee un poder independiente para desafiar de forma directa el statu quo [8]. A la gente le gustaría creer que los medios van a salvaguardar el medioambiente, por ejemplo, o que nos alertarán de condiciones medioambientales peligrosas. Sin embargo, muy pocos periodistas creen que ellos participan en el control y la defensa de los intereses sociales en esos términos, sino que, más bien, actúan como meros difusores e intérpretes de noticias e informaciones.

En los medios más generalistas debería aflorar la figura de la opinión bien documentada de alguien que comente la actualidad, sobre todo los programas y proyectos, desde las premisas del pensamiento ecológico. El analista o comentarista de opinión ecológico debe acabar no sólo apareciendo sino consolidándose. Hay que ser conscientes de las consecuencias o, como mínimo, ser capaces de minimizar los efectos negativos de las mismas desde antes de que se presenten en el escenario, aunque esto es algo que brilla por su ausencia [9].

La divulgación científica de calidad ha mejorado, sin duda, lo que permite aspirar a que se incremente todo lo relacionado con este campo. Desde la frecuencia a la intensidad y, aún más, a la calidad. Se les escapa todavía a los directores de los medios que, por primera vez, en la historia de la comunicación a través de sistemas masivos hay un tipo de vulgarización de los conocimientos que queda emparentada, por más de un eslabón, a la sociedad en su conjunto y, por tanto, a la vida cotidiana. También cabe vislumbrar un incremento de las informaciones, debates, comentarios, sobre todo el conjunto de tecnologías que nos permitan el cambio de modelo energético y que, en no poca medida, van a ser del dominio privado.

La información ambiental [10], ha conseguido en los últimos años hacerse con un espacio propio en algunos medios de comunicación o bien, y esto es más interesante, impregnar al resto de las secciones informativas y hacerse un hueco en ellas cuando las características de la noticia así lo precisan. Lo todavía infrecuente es encontrar a "periodistas" realmente especializados en estas cuestiones.
Julio - Diciembre 2015

ISSN 0122-820X

E-ISSN 2422-5053

PP: 34-53 
No. 2

Julio - Diciembre 2015 ISSN $0122-820 \mathrm{X}$ E-ISSN 2422-5053

PP: $34-53$
Los problemas ambientales de amplia dimensión, como el cambio climático, se perciben con cierta abstracción [11]. La ciudadanía accede al conocimiento del problema a través de la información científica que se filtra por las de instituciones mediadoras, principalmente los medios de comunicación. Son éstos los que reinterpretan y adaptan los aportes científicos en función de distintos fines, intereses, criterios, valores, públicos destinatarios, contextos sociales, etc.

Los medios populares de comunicación suelen ser la fuente primaria de información para el público general, incluyendo los propios científicos [12]. Es preciso que consideremos los medios como foros en los que se negocian los asuntos de interés público, por lo que su papel en la construcción social del calentamiento global, del efecto invernadero y el cambio climático, es clave.

Aunque la geografía donde se generan los problemas más graves del medio ambiente no proceden de las naciones en vías de desarrollo, sino de las regiones más industrializadas del mundo [13]. Por lo que es oportuno fundamentar argumentos y estrategias de comunicación que alcancen específicamente a las poblaciones del llamado Primer Mundo, y que pasan por el empleo de los medios masivos $\mathrm{y}$, en especial, de los públicos, con una clara orientación de inteligencia crítica.

Las teorías sobre desarrollo sostenible, tratan tanto de los problemas de los países pobres como del futuro funcionamiento de las sociedades en los países más ricos, [14]. Un desarrollo sustentable es aquel en el cual las necesidades de la generación actual son satisfechas sin poner en peligro la posibilidad de satisfacer las necesidades de las generaciones futuras. Por ello, debemos poner un límite para el crecimiento económico basado en actividades que agotan los recursos del planeta y lo contaminan enormemente, creyendo que se dispone de un acceso ilimitado a la naturaleza y sus recursos.
En tal caso, si el periodismo ambiental trata la información generada en la interacción del hombre o los seres vivos con su entorno o del entorno en sí, el periodismo sostenible trataría la información preeminentemente ambiental, económica o social que afecte a la disponibilidad de los recursos de las generaciones futuras [15].

\subsection{El periodismo ambiental en Colombia}

El origen de esta especialidad periodística se ubica en los años 70, cuando los activistas ecológicos Aníbal Patiño y Carlos Alfredo Cabal difunden sus diagnósticos ambientales en los departamentos del Cauca y Valle del Cauca. Ellos, además, denunciaron prácticas antiecológicas como la contaminación de los ríos provocada por desechos industriales. Estas denuncias tuvieron eco entre los diarios de Cali, El Occidente y El País, medios de comunicación que también colaboraron para la organización de foros en los que se discutía este tipo de problemas [16]. En esta misma década, un programa de televisión ícono de periodismo ambiental fue Naturalia (19741993), dirigido por Álvaro Castaño Castillo y presentado por su esposa Gloria Valencia de Castaño, se transmite en la televisión nacional y en él se presentaba la exuberancia de la naturaleza para que los televidentes admiraran los recursos naturales del planeta. Paralelamente, el periódico El Espectador, con sede en Bogotá, publica informes medioambientales en su Magazín Dominical y da espacio a columnistas muy críticos que llamaron la atención sobre las afrentas al medio ambiente en el país.

En los 80, Aníbal Patiño, quien también se desempeñaba como docente e investigador, publica el libro "Ecología y compromiso social", con el cual denuncia las prácticas desarrollistas que atentan contra la flora y fauna local, nacional e, incluso, internacional, pero al mismo tiempo destaca las propuestas de desarrollo sostenible. 
Posteriormente, distintas instituciones como Conservación Ambiental imparten talleres ambientales a periodistas, y la empresa Anway empieza a otorgar el Premio al Periodismo Ambiental, mediante el cual galardona a las mejores piezas periodísticas de esa especialidad.

\subsection{El periodismo ambiental en España}

El periodismo ambiental español nace a mediados de los 70, años en que la comunidad empieza a denunciar temas relacionados con los desastres naturales y una posible incursión de la energía nuclear en este país [17]. A partir de este momento, el medio ambiente ha sido objeto de debate político y científico debido a que hay más conciencia sobre la gravedad de los riesgos ecológicos que amenazan el planeta. Esta nueva actitud coincide con las Cumbres de la Tierra de Estocolmo en 1972 y de Río de Janeiro en 1992.

No significa que antes no se publicara información sobre este tema, sino que es desde esta fecha donde los españoles expresan más preocupación por las consecuencias negativas que pueden causar las malas prácticas ambientales. Sin embargo, esta información era más anecdótica y no prestaba atención a las causas de los problemas [18].

Hoy los problemas medioambientales, especialmente el del cambio climático, aparecen en los principales medios de comunicación, revalidando la necesidad de avanzar a un periodismo ambiental de excelencia.

\section{Preguntas de Investigación}

Partiendo de los anteriores referentes teóricos procedimientos a responder las siguientes preguntas de investigación en los dos planos de análisis empleados en este trabajo:

\subsection{En el plano de los textos informativos- interpretativos}

¿Cuáles temas y subtemas son los que predominan en la información medioambiental de los periódicos generalistas nacionales de Colombia y España? Y ¿qué tipo de actualidad y recursos aparecen en estos temas y subtemas?.

¿Cuáles son los tipos de titular, géneros periodísticos, tratamiento fotográfico $\mathrm{y}$ fuentes más usadas, así como las secciones, origen geográfico, los encargados de redactar esta información, su nivel de especialización, y la importancia que los dos periódicos le conceden a estos contenidos?.

¿Existe sensacionalismo en la información medioambiental, hay tecnicismos que se explican en estos textos, se presenta sensacionalismo en ellos? ¿Encontramos concienciación medioambiental?.

\subsection{En el plano de los textos de opinión}

¿Cuáles son los géneros de opinión más utilizados, la sección donde se publica la información medioambiental, su nivel de especialización y quiénes la redactan? ¿Existe sensacionalismo o falta de conciencia ambiental en las informaciones medioambientales de los periódicos El Espectador y El País?.

\subsubsection{Reseña del periódico El Espectador}

El Espectador fue fundado en 1887 y es miembro de la Sociedad Interamericana de Prensa (SIP), de la Asociación Mundial de Periódicos (WAN por sus siglas en inglés), del Instituto de Prensa Internacional (IPI) $\mathrm{y}$ de la Asociación de Diarios Colombianos (ANDIARIOS).

Desde 1996 aparece en la web, para que los lectores puedan consultarlo, comentar, compartir textos, entre otras acciones que
Julio - Diciembre 2015 ISSN 0122-820X E-ISSN 2422-5053 PP: 34-53 
No. 2

Julio - Diciembre 2015 ISSN 0122-820X E-ISSN 2422-5053

PP: 34-53 facilita Internet. Según el sondeo de la empresa Cifras y Conceptos de la revista Semana [19], que recoge la opinión de 2.307 líderes de opinión, seleccionados entre empresarios, académicos, políticos y diferentes organizaciones sociales, de diecisiete departamentos del país y Bogotá, la página web de El Espectador es consultada en un $15 \%$, la revista Semana (18\%) y el periódico El Tiempo (20\%). En relación con los medios impresos, la Encuesta General de Medios en el 2012 [20], señala que El Espectador es el cuarto diario más leído en Colombia con 238.965 lectores. El más leído es El Tiempo con 1.150.376 lectores; el segundo ADN (gratuito), con 778.836 y Al Día Barranquilla (regional), con 429.525 .

El periódico fue propiedad de la familia Cano, luego pasó al Grupo Santo Domingo de Colombia y, actualmente, es del grupo Prisa de España, dueño también del Canal Caracol.

\subsubsection{Reseña de El País}

El País, fundado en 1976 y de propiedad del grupo Prisa, es el diario español de más difusión en dicha nación, incluida la prensa deportiva. El promedio de tirada fue de 400.212 ejemplares y el promedio de difusión de 324.814, datos correspondientes al periodo de enero a diciembre de 2012 . Según los resultados del Estudio General de Medios de julio de 2013, la edición impresa llegó a 1.929.000 lectores y, además, es el líder en español en Internet, con 15.600.000 lectores únicos (medición de abril de 2013). Cuenta con más de 3.000 .000 de seguidores en Twitter y 700.000 en Facebook.

El periódico se publica en español, aunque también tiene algunas secciones en otros idiomas, como el catalán. La redacción central se localiza en Madrid, sin embargo, posee delegaciones en Barcelona, Sevilla, Valencia, Bilbao, Santiago de Compostela, ciudades desde las cuales edita contenidos territoriales.
El País cuenta con edición internacional que se imprime y distribuye en América Latina.

\section{Materiales y métodos}

\subsection{Análisis de contenido}

El método de investigación que se empleará para resolver las preguntas e hipótesis del estudio es el análisis de contenidos. Este método será el adecuado teniendo en cuenta las características y los propósitos de esta investigación, fundamentados en establecer diferencias y similitudes de la información ambiental manejada por los periódicos nacionales generalistas El Espectador de Colombia y El País de España.

Se recogen diversas definiciones [21] de lo que se entiende como análisis de contenidos; de esta manera, varios autores manifiestan que "el análisis de contenidos es un método de estudio y análisis de comunicación de forma sistemática, objetiva y cuantitativa con la finalidad de medir determinadas variables".

Entre las propiedades de este método está la posibilidad de generar análisis descriptivos que dan cuenta de la evolución de un fenómeno en un largo periodo de tiempo, o por ejemplo cambios sociales, valores o transformaciones en la opinión pública. Además, por su aspecto cuantitativo, permite ser más exacto y de la manodelaestadísticacomoherramientacentral ayuda al investigador en la amplificación e interpretación de los resultados obtenidos. Por su parte [22], se sostiene que la aplicación de este método a los contenidos de la prensa, radio, Internet, televisión y publicidad permite obtener resultados sobre cómo estos medios visualizan a la sociedad. Por lo anterior, los resultados obtenidos en esta investigación provenientes de la aplicación de un sistema de categorías a un medio escrito como la prensa, permiten arrojar datos que demuestran la importancia que cada periódico le concede a la información sobre el medio ambiente, así 
como características particulares referidas al nivel de especialización de este tipo de textos.

\subsection{Planos de análisis}

En este estudio se examinan tres planos de análisis en los que se utiliza el análisis de contenidos, así:

Primer plano: comprende la producción de información ambiental desde los géneros

Tabla I. Evaluación de variables en los periódicos

\begin{tabular}{|l|l|l|}
\hline \multirow{2}{*}{ 1. Tamaño } & Titular a 2 columnas & 2 \\
\cline { 2 - 3 } & Titular a 3 o más columnas & 3 \\
\hline \multirow{2}{*}{ 2. Espacio } & Más de 3/4 de página incluidas fotografias & 1 \\
\hline \multirow{2}{*}{ 3. Lugar de la página } & Si aparece en la 1/2 superior & 1 \\
\hline \multirow{3}{*}{ 5. Ilustraciones } & Noticia principal en portada & 2 \\
\cline { 2 - 4 } & Otras formas de aparición en portada & 1 \\
\cline { 2 - 4 } & Aparición en portada de sección o contraportada & 1 \\
\hline & Infográficos & 1,5 \\
\hline & Fotografías & 0,5 \\
\hline \multirow{2}{*}{ Puntuación Máxima } & & 10 \\
\hline
\end{tabular}

Fuente: Autores

Con esta ficha de medición asignamos una puntuación concreta a cada artículo que corresponde con la suma de cada elemento y en la que alcanzamos un máximo puntuable de 10 y un mínimo de 0 . De acuerdo con este sistema de puntuación se establece el siguiente baremo de importancia.

Tabla II. Baremo de puntuación

\begin{tabular}{|l|l|}
\hline Máximo interés & de 8 a 10 \\
\hline Alto interés & de 6 a 7,9 \\
\hline Interés medio & de 4 a 5,9 \\
\hline Bajo interés & de 2 a 3,9 \\
\hline Mínimo interés & de 0 a 1,9 \\
\hline
\end{tabular}

Fuente: Autores informativos e interpretativos. Aquí se incluye el nivel de especialización, presencia de sensacionalismo, utilización de fuentes, ubicación del contenido en secciones, etc. Como aspecto novedoso, incorporamos la Escala de Budd [23] actualizada, que permite medir la importancia que los periódicos regionales generalistas le dan a la información ambiental, con base en los baremos empleados en las siguientes tablas.
Segundo plano: comprende la producción de información ambiental desde el género de opinión. Aquí disminuyen las categorías de análisis por la misma naturaleza de este género. Así, se incluye nivel de especialización, la identificación del redactor del texto, etc.

\subsection{Muestras} 0122-820X 2422-5053 PP: $34-53$ 
No. 2

Julio - Diciembre 2015 ISSN 0122-820X E-ISSN 2422-5053 de seriedad informativa en el ámbito nacional e internacional.

- Son periódicos con gran cantidad de lectores, especialmente El País. Aunque El Espectador no es el más leído, si se encuentra entre los cuatro primeros en Colombia (ver reseñas 3.1 y 3.2 ).

- En un rastreo anterior al análisis se observó abundante información medioambiental, lo cual garantiza una muestra de contenidos amplia para su correspondiente codificación.

Muestra de contenidos. La muestra de contenidos se centró en el análisis del tema medioambiental y todos los subtemas que de él se desprenden. Por tal razón se excluyó otro tipo de información que maneja estos dos medios, y se procedió a clasificar todos los datos relacionados con el medioambiente ubicados en diversas secciones de los periódicos e incluidos en los géneros de información, interpretación y de opinión.
Muestra temporal. Para este trabajo se empleará una muestra aleatoria sistemática de semanas compuestas de los años 2009 y 2010 [24]. Una muestra de este tipo tiene una amplia argumentación científica en torno a su validez para estudiar medios impresos $\mathrm{y}$ audiovisuales. Al utilizar las semanas compuestas se evita la "periodización" de los contenidos, riesgo que puede estar de manifiesto cuando se utilizan las muestras simples, es decir, la selección de las muestras de los periódicos producto del azar, sin ningún intervalo justificado.

\section{Resultados y análisis}

Se encontraron 353 piezas de las que 286 fueron textos informativos-interpretativos (166 corresponden a El Espectador y 187 a El País) y 38 de opinión (10 de El Espectador y 18 de El País). A continuación se presentan los resultados de los planos informativos e interpretativos, y el de opinión.

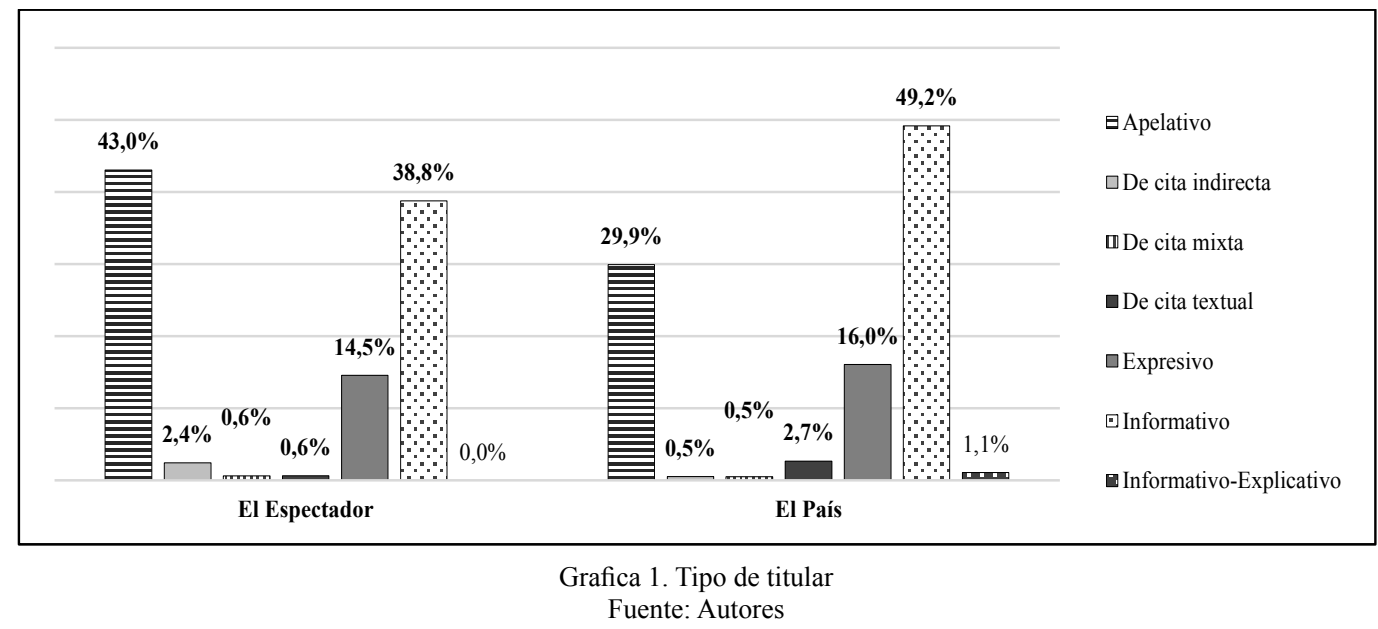

\subsection{Textos informativos e interpretativos}

De acuerdo con [25] pueden utilizarse tres maneras esenciales de titulación: los titulares expresivos, que no aportan datos sobre el hecho que relatan; titulares apelativos, que aportan un enfoque temático general; y titulares informativos, que serían todos los demás que se nombran, en la Grafica 1, y que identifican singularmente una determinada acción contemplada en el texto. De esta manera los dos diarios emplean titulares informativos, en la mayoría de los casos: El Espectador $38,8 \%$ y El País (49,2\%). Sin 
embargo, también son usuales los titulares apelativos (más en El Espectador, 43\% que en El País $(29,9 \%)$, con los que se busca llamar la atención con frases cortas y, a veces, sensacionalistas.

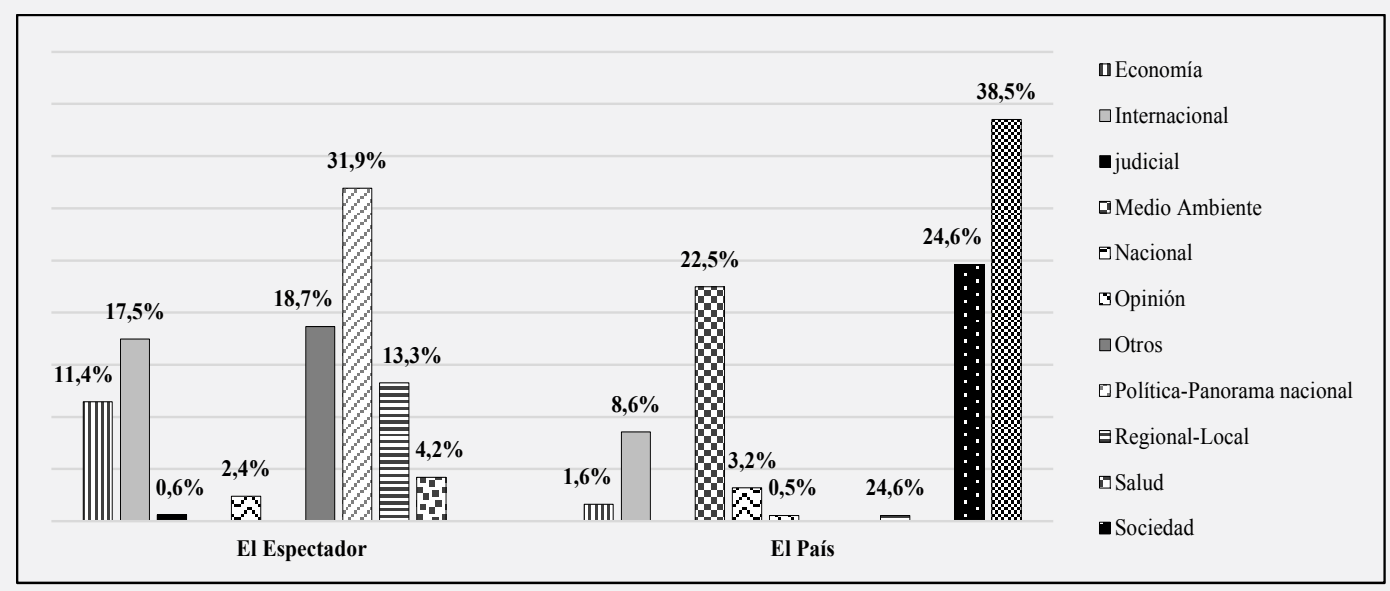

Grafica 2. Sección

Fuente: Autores
Julio - Diciembre 2015 ISSN 0122-820X

E-ISSN 2422-5053

La información ambiental se publica fundamentalmente en la sección política-panorama nacional (31,9\%) de El Espectador y en los Suplementos (38,5\%) de El País.

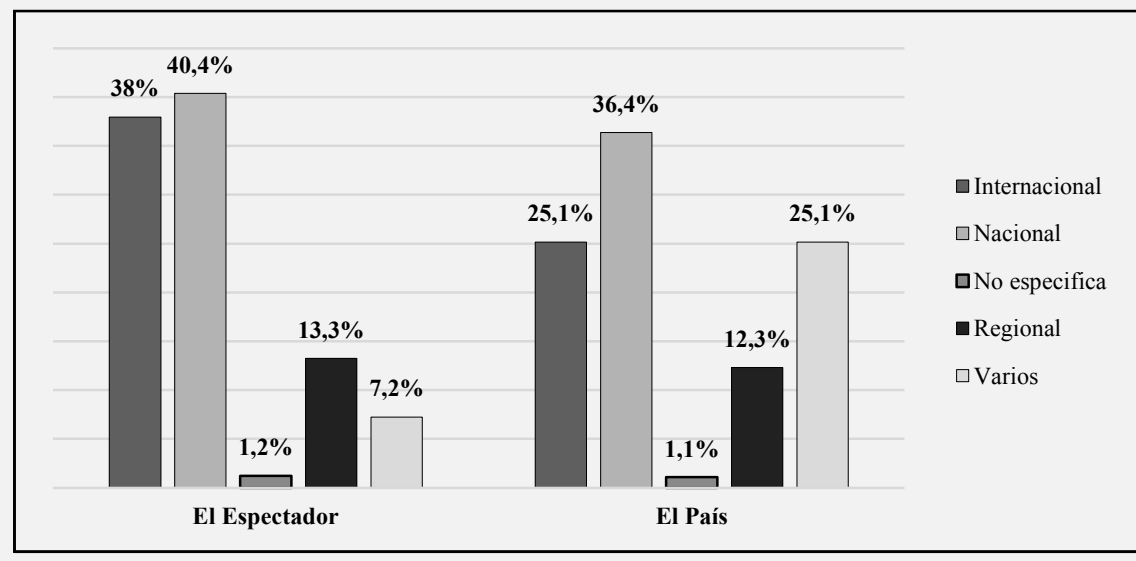

Grafica 3. Origen geográfico de la pieza Fuente: Autores

En otra investigación [26] se determinó que, tanto para El País como para El Espectador, resultan más importantes los hechos de carácter nacional que los de ámbito internacional o transnacional. Esto se debe especialmente a que ambos diarios concentran su atención en los asuntos que afectan directamente los intereses de los ciudadanos de sus respectivos países. En este estudio, también ha quedado constancia de que el origen geográfico de las informaciones ambientales se ubica en el ámbito nacional -tanto de El Espectador 40,4\% como de El País, 36,4\%- y en el internacional (El Espectador, 38\%; y El País, $25,1 \%)$. 


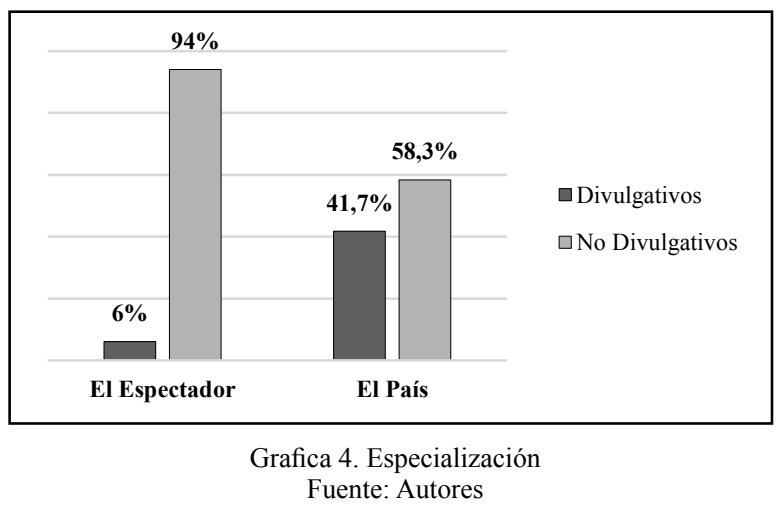

La casi totalidad de los textos en el periódico nacional de Colombia son poco especializados o no divulgativos (94\%); en el de España, la mayoría son más divulgativos (58,3\%), lo que implica que el manejo de los contenidos es más especializado o técnico.

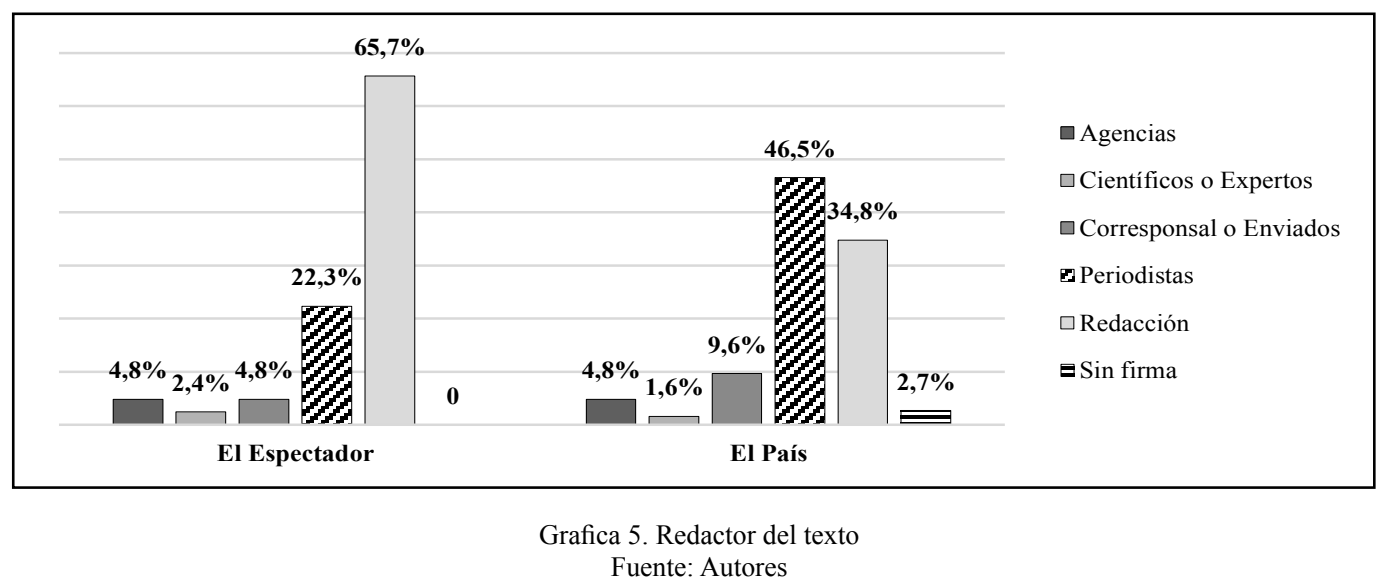

Los textos medioambientales están escritos mayoritariamente por los periodistas del medio con su crédito respectivo en el caso español (El País, 46,5\%), mientras que se denota a priori la falta de personal cualificado en el periódico colombiano (El Espectador, 22,3\%), donde recurren mayoritariamente a la firma de la Redacción $(65,7 \%)$ en temáticas que puedan ser más controvertidas, frente al 34,8 \% de El País. Llama la atención que en El Espectador existen más textos firmados por científicos o expertos $(2,4 \%)$ y en El País los corresponsales o enviados tienen un papel más activo en la redacción y rúbrica de las piezas medioambientales $(9,6 \%)$.

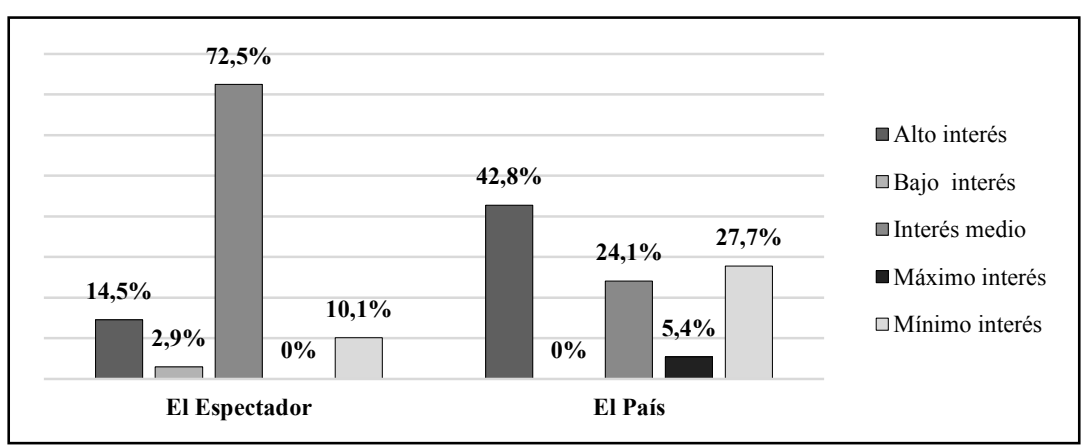

Grafica 6. Puntuación escala de Budd Fuente: Autores 
La importancia que el medio de comunicación le da a la información sobre medio ambiente es diferente. En El Espectador, esa relevancia se ubica en la categoría de interés medio (72,5\%), en tanto que en El País la importancia sobre estas temáticas está más repartida en las categorías de alto interés $(42,8 \%)$ y medio $(24,1 \%)$.

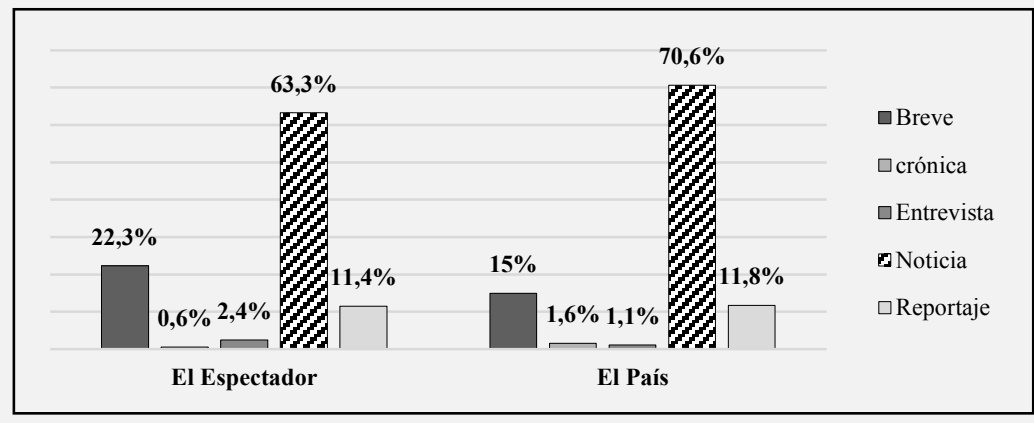

Grafica 7. Género periodístico Fuente: Autores

En ambos diarios hay un predominio por las piezas informativas, esto es, por la noticia (El Espectador, 63,3\% y El País, 70,6\%) y por los breves (El Espectador, 22,3\% y E1 País, 15\%). Hay poco espacio para crónicas, entrevistas y reportajes, géneros con los que se ofrece más contextualización y análisis a los temas ambientales.

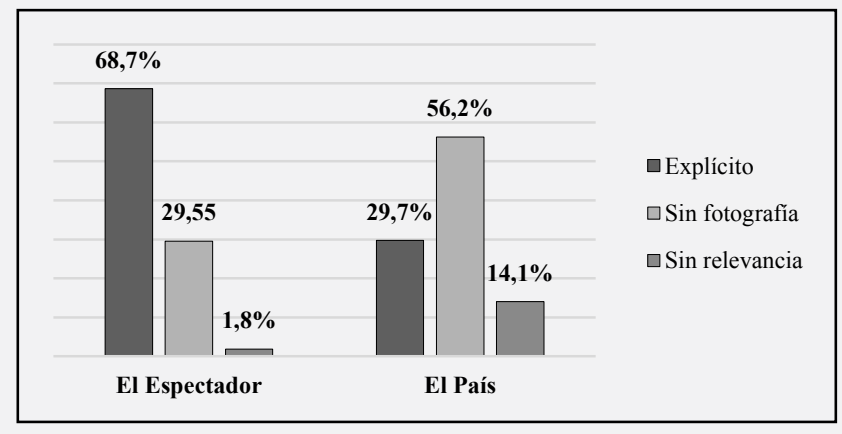

Grafica 8. Tratamiento fotográfico Fuente: Autores

Generalmente las piezas informativas de El Espectador van acompañadas de, al menos, una fotografía relacionada de manera explícita $(68,7 \%)$ con el tema ambiental de la zona afectada. No ocurre lo mismo con El País, cuyas páginas carecen de fotografías $(56,2 \%)$ que acompañen explícitamente a las informaciones ambientales.

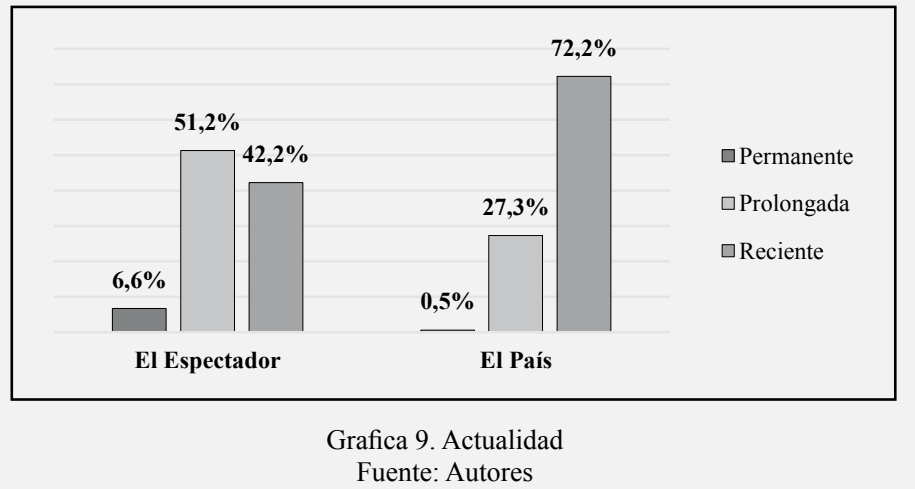


No. 2

Julio - Diciembre 2015 ISSN 0122-820X E-ISSN 2422-5053
La información medioambiental en los periódicos nacionales de Colombia y

España: un estudio comparativo

La mayoría de los autores consideran que la actualidad no es un concepto cerrado, sino más bien un "concepto relativo" que contribuye a configurar lo que entendemos por noticia. Otros autores [27] hacen una clasificación de los distintos tipos de actualidad que utilizamos en esta investigación. De esta manera encontramos que la actualidad de las temáticas ambientales que se tratan en El Espectador es mayoritariamente prolongada $(51,2 \%)$ y reciente $(42,2 \%)$, mientras que en El País lo es reciente (72,2\%).

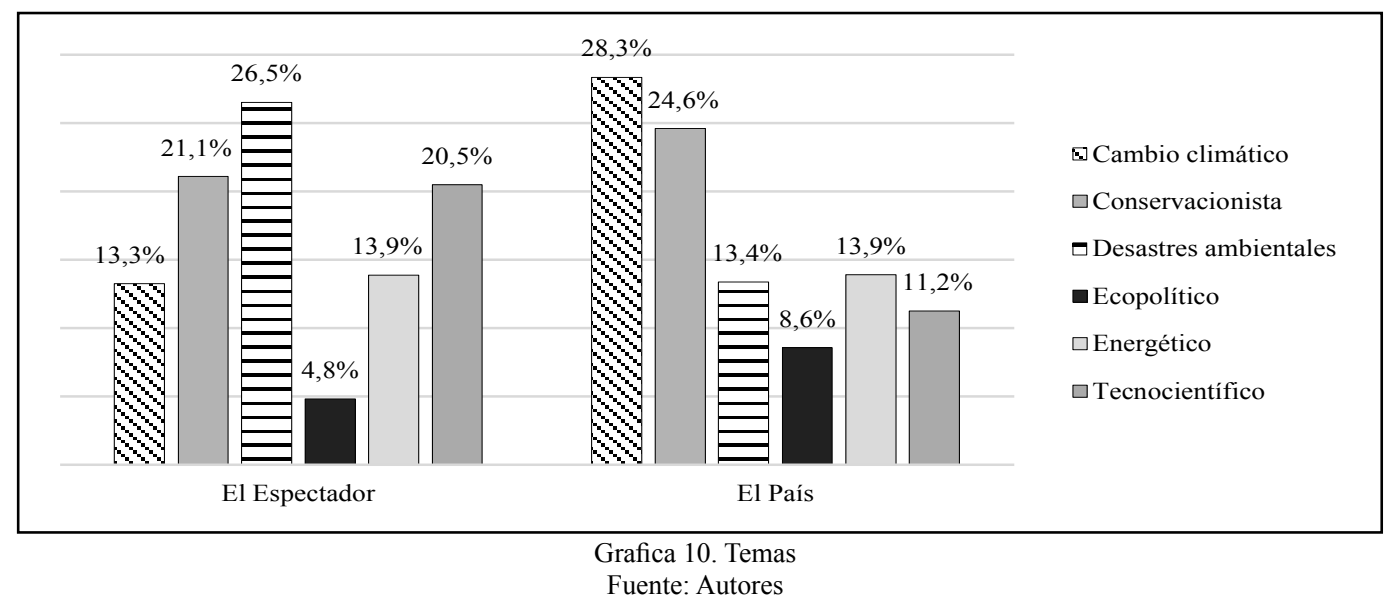

Para realizar esta clasificación temática hemos dividido las informaciones según los siguientes epígrafes de elaboración propia, obtenidos a partir del análisis de las piezas informativas encontradas en los medios. El tema que con más frecuencia se publica en los dos periódicos es el relacionado con los aspectos conservacionistas: El Espectador (21,1\%) y El País (24,6\%). Si se analiza cada medio de comunicación, se evidencia que en El Espectador predomina la temática de los desastres ambientales (26,5\%) y en El País la del cambio climático (28,3\%).

Tabla III. Subtemas

\begin{tabular}{|c|c|c|c|}
\hline $\begin{array}{l}\text { Subtemas } \\
\end{array}$ & EI Espectador & El País & Total general \\
\hline Aumento o disminución de emisiones de $\mathrm{CO} 2$ & $3,6 \%$ & $3,7 \%$ & $3,7 \%$ \\
\hline Aumentos de las temperaturas globales & $0,6 \%$ & $1,1 \%$ & $0,8 \%$ \\
\hline Contaminación de aire, agua y suelo & $1,2 \%$ & $1,6 \%$ & $1,4 \%$ \\
\hline Cumbres y reuniones ambientales & $3,0 \%$ & $1,1 \%$ & $2,0 \%$ \\
\hline Definición y aplicación de políticas ambientales... & $1,2 \%$ & $5,9 \%$ & $3,7 \%$ \\
\hline Desastres No provocados por el hombre & $24,1 \%$ & $8,0 \%$ & $15,6 \%$ \\
\hline Desastres provocados por el hombre & $1,8 \%$ & $3,2 \%$ & $2,5 \%$ \\
\hline Eliminación de desechos & $0,6 \%$ & $1,6 \%$ & $1,1 \%$ \\
\hline Energía nuclear & $3,6 \%$ & $5,3 \%$ & $4,5 \%$ \\
\hline Energías renovables & $1,8 \%$ & $4,3 \%$ & $3,1 \%$ \\
\hline Especies en peligro de extinción & $2,4 \%$ & $1,1 \%$ & $1,7 \%$ \\
\hline Flora, fauna y ecosistemas & $1,8 \%$ & $7,0 \%$ & $4,5 \%$ \\
\hline Gestión de espacios naturales & $7,2 \%$ & $0,5 \%$ & $3,7 \%$ \\
\hline Investigaciones e innovaciones tecnológicas & $18,7 \%$ & $8,6 \%$ & $13,3 \%$ \\
\hline La alteración de los genomas de las plantas... & $0,6 \%$ & $2,7 \%$ & $1,7 \%$ \\
\hline Mitigación y adaptación al Cambio Climático... & $1,2 \%$ & $0,5 \%$ & $0,8 \%$ \\
\hline Otros & $21,1 \%$ & $42,8 \%$ & $32,6 \%$ \\
\hline Pérdida de biodiversidad & $0,6 \%$ & $0,5 \%$ & $0,6 \%$ \\
\hline Petróleo & $3,0 \%$ & $0,5 \%$ & $1,7 \%$ \\
\hline Redirección de aguas para construir edificios, carreteras, embalses & $1,8 \%$ & $0,0 \%$ & $0,8 \%$ \\
\hline Total general & $100,0 \%$ & $100,0 \%$ & $100,0 \%$ \\
\hline
\end{tabular}

Fuente: Autores

Los tres subtemas en ambos periódicos que poseen altos porcentajes son: desastres no provocados por el hombre, en El Espectador (24,1\%) y El País (8\%); investigaciones e innovaciones tecnológicas, en El Espectador (18,7\%) y El País (8,5\%); otros, categoría que se refiere, fundamentalmente, al estado del tiempo, en El Espectador $(21,1 \%)$ y El País $(42,8 \%)$. Este último 
dato permite inferir que no existe una preocupación profunda en ambos diarios, principalmente en El País, por abordar y profundizar otros subtemas medioambientales.

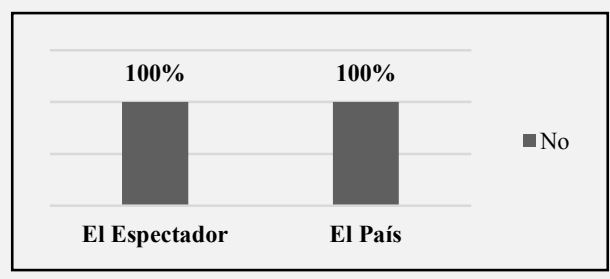

Grafica 11. Sensacionalismo Fuente: Autores

No hay presencia de sensacionalismo en El Espectador de Colombia ni en El País de España.

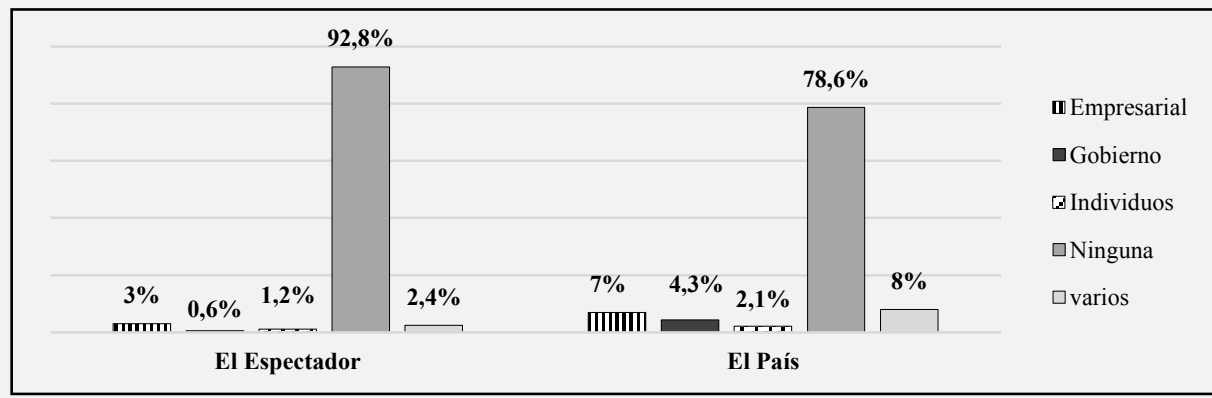

Grafica 12. Falta de conciencia ambiental Fuente: Autores

No hay falta de conciencia medioambiental en los diferentes actores en el periódico colombiano El Espectador, y es muy poco significativa en el periódico español El País, donde el egoísmo o la falta de solidaridad por parte de los individuos en materia de reciclaje o en temas como el transporte público se da sólo en un $7 \%$ en el ámbito empresarial y en un 4,3\% en el gobierno.

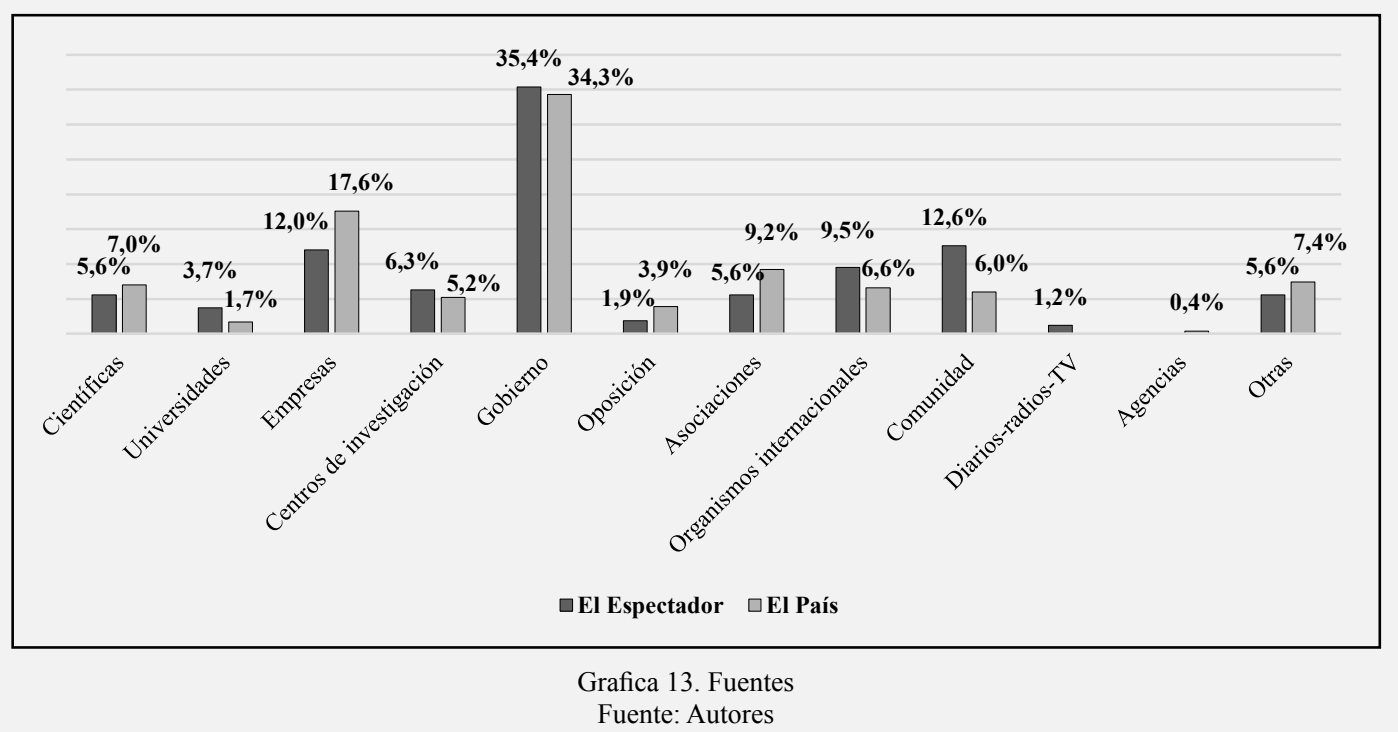

Tanto El Espectador (35,4\%) como El País (34,3\%) citan asiduamente al gobierno. Respecto a otras fuentes, las empresas se consultan con más frecuencia en El País (17,6\%) que en El Espectador 
$(12,0 \%)$, pero los centros de investigación y la comunidad tienen porcentajes más altos en El Espectador (6,3\% y 12,6\%, respectivamente) que en El País (5,2\% y 6,1\%, respectivamente).

\subsection{Textos de opinión}

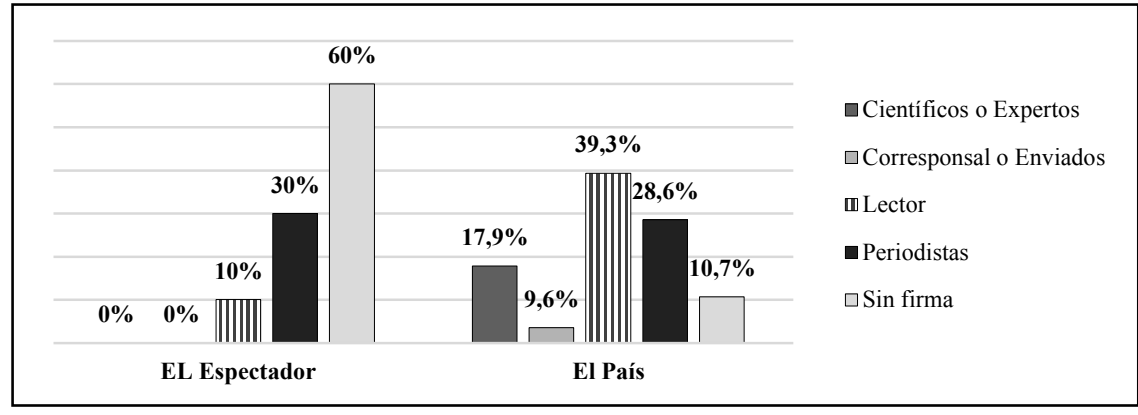

Grafica 14. Redactor del texto

Fuente: Autores

La mayoría de los textos de opinión no aparecen firmados (60\%) en El Espectador y solo un 30\% de ellos están firmados por periodistas. En El País, los lectores en un 39,3\% de los casos, firman esas piezas y sus periodistas hacen lo mismo en un $28,6 \%$.

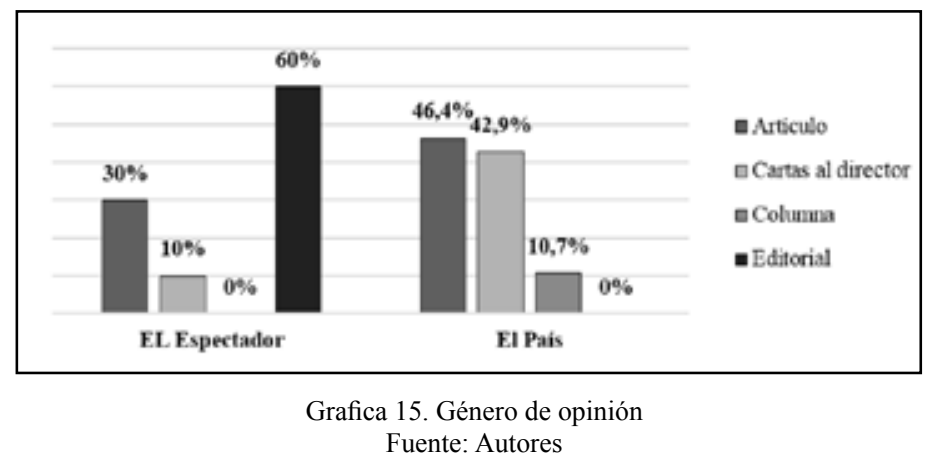

Cabe destacar que el 60\% de las piezas en El Espectador se expresan a través de editoriales, donde se redacta la posición del periódico sobre un tema de actualidad, en este caso, sobre contenidos medioambientales. Los artículos también aparecen en un porcentaje significativo (30\%). En El País, la mayoría de la opinión se expresa mediante artículos $(46,4 \%)$ y cartas al director $(42,9 \%)$.

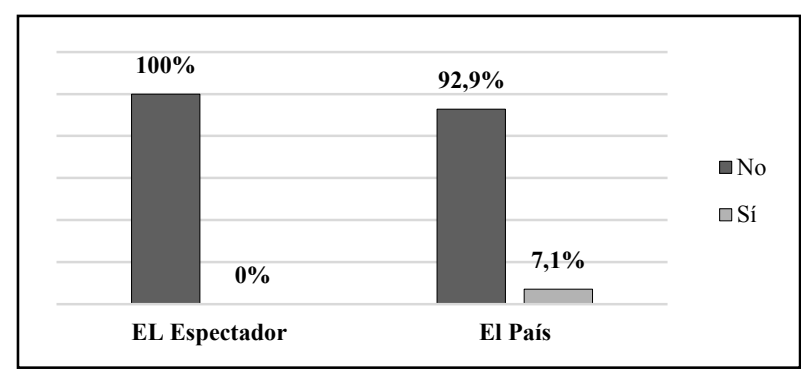

Grafica. 16. Sensacionalismo Fuente: Autores 
En el caso de los textos informativos, [28] se estudia la valoración del texto periodístico evaluando el hecho noticioso y sus consecuencias, definiendo al sensacionalismo como aquel en el que "el autor valora exageradamente el hecho para tratar de llamar la atención del lector, otorgándole una trascendencia mayor de la que el hecho tiene en realidad, pudiendo incurrir casi en la mentira". Otra evidencia destacable se da cuando en El Espectador de Colombia donde no encontramos ningún atisbo de sensacionalismo en los géneros de opinión que tratan temáticas medioambientales. En El País de España, sí, aunque con un porcentaje bajo (7,1\%).

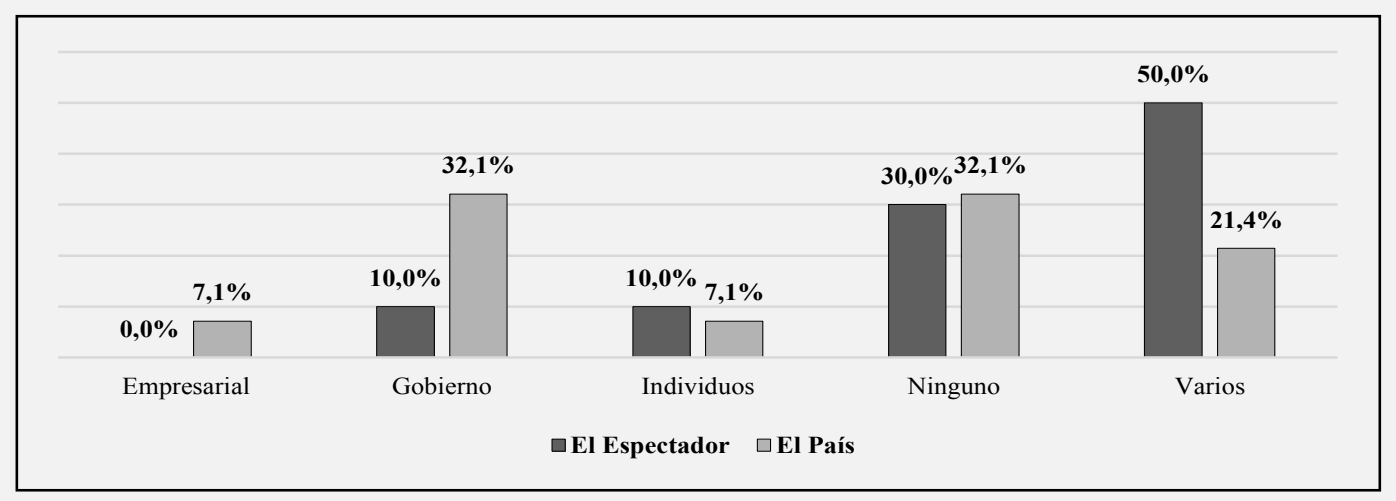

Grafica 17. Falta de conciencia ambiental Fuente: Autores

La categoría de falta de conciencia ambiental se identifica en El Espectador en la categoría varios $(50 \%)$, mientras que en El País recae en el gobierno $(32,1 \%)$. En una tercera parte de las piezas de opinión de ambos medios no se identifica a un responsable.

\section{Conclusiones}

En general podemos decir que existen similitudes y diferencias entre los periódicos nacionales de ambos países sobre cómo abordan las temáticas medioambientales. El País lo hace de manera más especializada o técnica $(41,7 \%)$ que El Espectador (6\%), lo cual significa que existe más interés porque los contenidos sean de excelencia. Sin embargo, ambos utilizan géneros periodísticos como la noticia $(63,3 \%$ en El Espectador y $70,6 \%$ en El País), en detrimento de géneros interpretativos como el reportaje y la crónica que añaden contextualización y profundidad. Las noticias y, mucho menos los breves, no proporcionan el espacio suficiente para incluir más datos, fuentes y reflexiones atractivas, de manera que se incremente la calidad de estos textos.
Estos medios presentan la información ambiental en un tono de interés medio $(72,5 \%)$ en el caso de El Espectador y alto (42,8\%) en El País, sin toques de sensacionalismo y con titulares mayoritariamente informativos en El País $(38,8 \%)$ y apelativos $(43 \%)$ en El Espectador, aunque si se suma el género de los breves, se podría concluir que los titulares de los dos medios pretenden fundamentalmente informar más que llamar la atención. Estos aspectos, en parte ayudan a que los lectores puedan tener más información para comprender los fenómenos ambientales. Se resalta el hecho de que las directivas de El País le dan mucha importancia a la información ambiental, situación que debe tener en cuenta El Espectador, pues es un tema que cada día cobra más relevancia para la sociedad.

En la mitad de los casos se tratan temas nacionales (E1 Espectador, 40,4\% y El País, 36,4\%) que están de candente actualidad, reciente y prolongada, con textos redactados mayoritariamente por periodistas y la redacción, en los que el medio ambiente es la idea central sobre la que gira la información y los desastres am- 
No. 2 bientales, la temática más tratada $(26,5 \%)$ en El Espectador y el cambio climático $(28,8 \%)$ en El País. Si bien es cierto que son temas de actualidad, estos medios de comunicación no deben escatimar esfuerzos para abordar otros contenidos que impliquen la curiosidad de los lectores y, promuevan, comportamientos medioambientales positivos.

El subtema que más se aborda son los desastres provocados por el hombre $(24,1 \%)$ en el periódico colombiano, en tanto que en el español el subtema categorizado como "otros", que involucra múltiples aspectos relacionados con el cambio climático, es el que predomina $(42,8 \%)$. En esta última cifra, se compendian textos relacionados con predicciones del clima, lo cual es importante para que las personas puedan programar su día a día. No obstante, esos espacios se deben complementar con contenidos educativos que desarrollen capacidades en los lectores para la conservación y preservación de todo lo que les rodea, con carácter sostenible.

Los temas ambientales son materia de discusión y debate político en Colombia, pues este tipo de contenidos aparecen con mucha frecuencia en la sección política-panorama nacional $(31,9 \%)$, mientras que estos se publican asiduamente en los suplementos $(38,5 \%)$ de El País. No existe una falta de conciencia medioambiental por parte de los diferentes actores que aparecen en estas piezas informativas dentro del periódico español y es muy poco significativa en el caso colombiano. Ambos medios dan prelación al gobierno como fuente $(35,4 \%$ en El Espectador y $34,5 \%$ en El País), lo cual sugiere que hay cierta dependencia hacia las declaraciones e informes oficiales. Llama la atención que en el diario colombiano las piezas se publican con fotografías en la mayoría de los casos y estas tienen un carácter explícito $(68,7 \%)$, es decir, que tanto texto como imagen guardan cierta correspondencia y relevancia, pero en el diario español más de la mitad de sus piezas $(56,2 \%)$ no van acompañadas de una fotografía.

Estos datos justifican la percepción general que queda después del análisis: la falta de un sentido más crítico frente a los desastres ambientales y a las concepciones de desarrollo extrativista que poco ayudan a mantener el equilibrio ecológico. La escasa presencia de universidades y centros de investigación, así como de las voces de la comunidad y de los movimientos sociales, refuerzan la idea de que en los dos diarios existe una postura más oficialista sobre los temas ambientales, situación que no permite tener en cuenta expresiones alternativas que puedan realizar un diagnóstico real de lo que ocurre en la tierra en materia ambiental.

En el caso del periódico El País, los contenidos de opinión ambiental se difunden mediante artículos $(46,4 \%)$, mientras que en el caso colombiano la directiva del medio está más concienciada con estos temas, ya que tiene un mayor número de editoriales publicados $(60 \%)$, frente al periódico español, en el que son los lectores con sus cartas $(42,9 \%)$, los que más se interesan.

Cabe destacar que el diario colombiano presenta los textos de opinión medioambiental sin tintes sensacionalistas, situación que no ocurre en el periódico español donde sí aparecen rastros de esta categoría $(7,1 \%)$. Respecto a la falta de conciencia ambiental, la responsabilidad recae en "varios" (50\%) en El Espectador y el gobierno (32,1\%) en El País.

Algunos medios como el prestigioso diario Le Monde ya tiene su sección diaria de medio ambiente. El País al igual que otros periódicos españoles como La Razón, El Mundo y ABC cuenta ya con un suplemento mensual de medio ambiente. También se palpa un aumento considerable de las noticias ambientales en los informativos de las cadenas de televisión 
españolas, así como en los medios locales. Aunque el boom de la información ambiental se ha producido en Internet y es a través de este canal, sobre el que nos atrevemos a predecir que se construirá el futuro del Periodismo Ambiental.

Esta especialidad, pasa porque existan noticias en torno a la misma. En eso podemos estar tranquilos, o se debería decir intranquilos, porque siempre que los medios recogen información ambiental es porque se ha producido alguna catástrofe importante. Los responsables de los medios de comunicación parece que están empezando a recapacitar, quizás se han dado cuenta de que los grandes problemas del planeta pasan, irremediablemente por el medio ambiente, y que con una buena información ambiental se conocerá qué se está haciendo bien o qué se está haciendo mal en otras actividades como la económica.

Si estableciéramos qué puede aportar El Espectador a El País y viceversa en tratamiento de la información medioambiental, podríamos señalar que El Espectador (I) posee más editoriales con lo cual se nota un compromiso de sus directivas por el abordaje de esta temática; (II) cuenta con más fotografías explícitas sobre estas piezas medioambientales y (III) no añade sensacionalismo a sus informaciones. Por su parte, El País (I) tiene notas más especializadas; (II) con un interés más alto gracias a que incorpora más recursos periodísticos y (III) publica suplementos, de modo que suministra más contenido especializado a sus lectores. Ambos diarios, no obstante, deben procurar ser más críticos, incluir más variedad temática y fuentes alternativas de información ambiental, así como más espacios educativos para el abordaje periodístico del medio ambiente. Por último, es pertinente sugerir, además, que los dos periódicos avancen en la actualización y formación permanente de sus periodistas en temáticas ambientales y que la sección investigativa incorpore temas de este tipo, para que los textos que se publiquen sean de excelencia y coadyuven a generar comportamientos loables para la protección medioambiental.

\section{Referencias}

[1] L. Guijarro, "Periodismo Ambiental una realidad en alza", Ambienta: la revista del Ministerio de Medio Ambiente, no. 74, pp. 71-77, 2008.

[2] R. Fernández Reyes, "En torno al debate sobre la definición del periodismo ambiental", Ámbitos: Revista internacional de comunicación, no. 9-10, pp. 143-151, 2003.

[3] S.Fernández, "Lainformaciónambiental en los medios de comunicación. Dificultados y retos", Telos: Cuadernos de comunicación e innovación, no. 68 , pp. 109-115, 2006.

[4] M. Montaño, "Periodismo ambiental en Canal Sur Televisión", Ámbitos: Revista internacional de comunicación, no.1, pp. 223-230, 1998.

[5] R. F. Reyes, Aproximación a la bibliografía del periodismo ambiental iberoamericano. Razón y palabra, no. 77, 2011.

[6] J. Fernández Sánchez. Periodismo Ambiental en España. Ministerio de Obras Públicas, Transportes y Medio Ambiente, Madrid. 1995. 0122-820X 422-505 $34-53$ 
No. 2

Julio - Diciembre 2015 ISSN 0122-820X E-ISSN 2422-5053

PP: $34-53$ industria y audiencias". Infoamérica: Iberoamerican Communication Review, no. 1, pp. 5-23, 2009.

[9] J. Araujo, "El futuro de la comunicación ambiental". Mètode: Revista de difusión de la Investigación, $\mathrm{N}^{\circ} .66$, pp. 84-86, 2010.

[10] J.M.Montero, "Medios decomunicación y medio ambiente" en Actas de la VIII aula de ecología educación ambiental: Almería, 1994, pp. 89-101.

[11] R. Fernández, "Irrupción mediática y representación ideológica del cambio climático en España", Contribuciones a las Ciencias Sociales. No. 10, 2010. [Online]. Disponible en: http://www. eumed.net/rev/cccss/10/.

[12] M. A. Cuello, "Ciencia, política y comunicación: Una aproximación a la construcción social del cambio climático en "an inconvenient truth", Cultura verde: ecología, cultura y comunicación, pp. 261-284, 2007.

[13] B. Díaz Nosty, "Cambio climático, consenso científico y construcción mediática. Los paradigmas de la comunicación para la sostenibilidad". Revista Latina de Comunicación Social, No. 64, pp. 99-119, 2009.

[14] V. Stoehrel, "Chile y el mundo: Cambio climático, medioambiente y sociedad". 2009. [Online]. Disponible en: http://www.razonypalabra.org.mx/ CHILEYELMUNDOLIBRO.pdf.

[15] R. F. Reyes, "Periodismo ambiental y periodismo sostenible". Ámbitos: Revista internacional de comunicación, no. 11, pp. 311-317, 2004.

[16] K. N. Arias y C. F. Galván, “Tratamiento informativo del tema medioambiental en los periódicos: El Colombiano, El Espectador y El Tiempo mediante el análisis de contenidos", Tesis para optar por el Titulo de Comunicador Socialperiodista, Universidad Pontificia Bolivariana de Bucaramanga, 2011.

[17] L. C. Vargas y N. Daniels, "La agenda informativa medioambiental de los periódicos generalistas de España y Colombia: un estudio comparativo". Tesis de grado la Universidad del Tolima, 2013.

[18] L. Guijarro, "Periodismo ambiental: una realidad en alza", Ambienta: la revista del Ministerio de Medio Ambiente, no. 74, p. 71, 2008.

[19] Semana. Encuesta de líderes I. 2014. [Online]. Disponible en: http://www. semana.com/confidenciales/articulo/ encuesta-de-lideres/407792-3.

[20] Noches de media. Último EGM: El Tiempo es el más leído del país; gratuitos y populares siguen consolidándose. 2012. [Online]. Disponible en: http:// nochesdemedia.com/2012/11/21/ ultimo-egm-el-tiempo-es-el-mas-leidodel-pais-gratuitos-y-populares-siguenconsolidandose/.

[21] R. Wimmer \& J. Dominick. La investigación científica de los medios de comunicación social. Una introducción a sus métodos. Barcelona: Editorial Bosch, 1996.

[22] T. Velásquez, "Técnicas cuantitativas: el análisis de contenidos" En La investigación en comunicación, L. Vilches, Barcelona, España: Gedisa Editorial, pp. 117-141, 2011.

[23] R. W. Budd, "Attention score: a device for measuring news play", Journalism \& Mass Communication Quarterly, no. 41. pp. 259-262, 1964. 
[24] I. Zabaleta Urkiola. Komunikazioaren ikerkuntzarako metodología. Bilbao: UEU, 1997.

[25] L. Núñez Ladevéze, "El título periodístico informativo", en Manual para periodismo. Barcelona: Ariel, 1991, pp. 219-241.

[26] L. Gutiérrez Coba, "Temas de interés para los periódicos de prestigio: el caso de El País y El Espectador", Zer: Revista de estudios de comunicación, no.10, vol. 6, pp. 131-157, 2001.

[27] J. I. Armentia Vizuete y J. M. Caminos Marcet, La información: redacción y estructura. Guipuzkoa: Editorial Universidad del País Vasco, 1998.

[28] A. Fernández Muerza, "Estudio del periodismo de información científica en la prensa de referencia: el caso español a partir de un análisis comparativo", Tesis Doctoral, Universidad del País Vasco, España, 2004. 